\title{
The pathology of experimental lead encephalopathy in the baboon (Papio anubis)
}

\author{
A. P. HOPKINS ${ }^{1}$ and A. D. DAYAN ${ }^{2}$ \\ University Department of Clinical Neurology and Department of Neuropathology, \\ National Hospitals for Nervous Diseases, Queen Square, London
}

\begin{abstract}
Hopkins, A. P., and Dayan, A. D. (1974). British Journal of Industrial Medicine, 31, 128-133. The pathology of experimental lead encephalopathy in the baboon (Papio anubis). Baboons(Papio anubis) were intoxicated by intratracheal injections of lead carbonate. The main pathological findings were of widespread cerebral oedema and focal cortical necroses. The mechanism by which lead produces these changes is not known.
\end{abstract}

Lead has very different effects in various species. In the rabbit for example it produces anaemia, punctate basophilia, and axonal degeneration without segmental demyelination; in the guinea-pig, segmental demyelination is the predominant lesion of the peripheral nerves; in the cat, both types of nerve lesion occur but punctate basophilia does not develop. These and other differences in other species are tabulated by Hopkins (1970).

Lead encephalopathy still occurs relatively frequently (Whitfield, Ch'ien, and Whitehead, 1972), but the nature of the histological lesions remains confused (see discussion and review by Pentschew (1958)). We have therefore investigated this problem in a primate, the baboon (Papio anubis).

\section{Methods}

Two adult and one infant baboon were studied. Lead carbonate was given by repeated intratracheal injections under light anaesthesia. Details of this procedure, and details of the diet, supplements of vitamin $B_{12}$, and general care of these animals are available in another publication (Hopkins, 1970). Seizures were observed either by one author (A.P.H.) or by trained animal technicians, and

1Present address: Department of Neurology, St. Bartholomew's Hospital, London EC1A 7BE

2Present address: Wellcome Research Laboratories, Langley Court, Beckenham, Kent, BR2 3BS daily notes were made of these and other clinical phenomena.

Brains were removed one to three hours after death and fixed by immersion in $10 \%$ formol saline. Coronal slices were embedded in celloidin or in paraffin wax. Sections were stained by conventional techniques; frozen sections stained with Scharlach $\mathbf{R}$ were employed to demonstrate the breakdown of myelin.

The brain of one control animal was prepared in this way, and histological examination showed no significant abnormalities.

\section{Results}

Observations on the changes in body weight and concentrations of haemoglobin and lead in the blood are shown in Figures 1 and 2. In spite of the high concentration of blood lead and the considerable weight loss, there was no change in the haemoglobin concentration.

\section{Baboon 3 (Fig. 1)}

Female $11.7 \mathrm{~kg}$. Five injections of lead carbonate, $1 \mathrm{~g}(86 \mathrm{mg} / \mathrm{kg}$ initial weight), were given on days 0 , $24,42,59$, and 122 and of $1.2 \mathrm{~g}$ on day 137 . There was a marked increase in irritability and aggressive behaviour by this animal as early as the eleventh day. This reaction was not seen in animals which were not injected but repeatedly handled in the same way. On day 149 the first seizure was observed. 


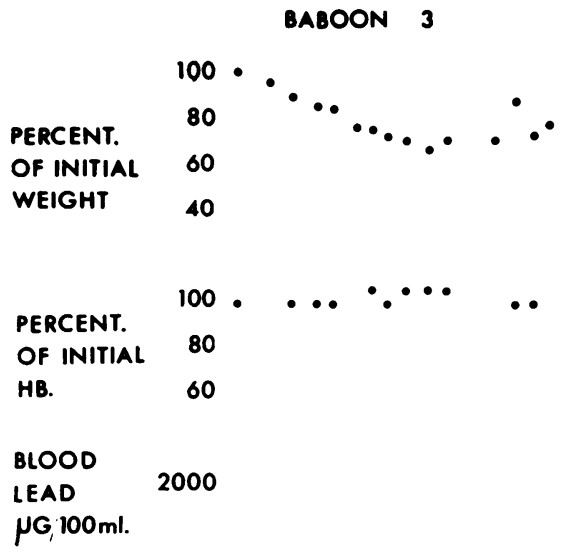

1000

\section{, Illillll , ,l}

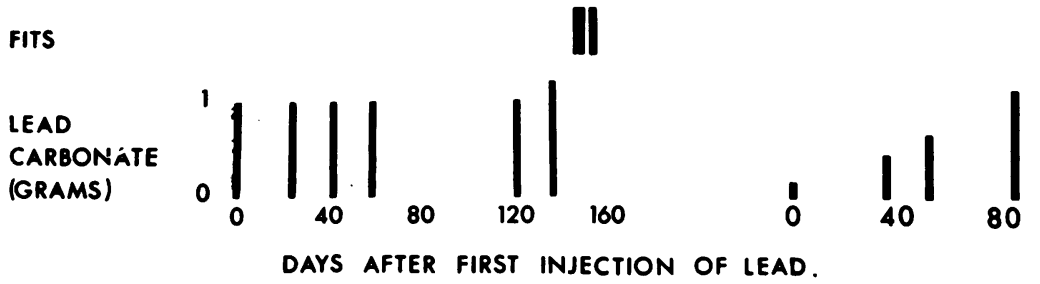

FIG. 1. Changes in body weight, in concentrations of haemoglobin and blood lead, and occurrence of fits after repeated intratracheal injections of lead carbonate in baboons 3 and 7B.
Twitching was seen to spread from the right side of the face to the arm before becoming generalized. Consciousness was recovered after about three minutes. There was no postictal paralysis. Phenobarbitone, $20 \mathrm{mg}$ intramuscularly, did not prevent a second seizure with focal onset about six hours later. Two more seizures were observed on days 150 and 151 . On day 154 a further generalized seizure was followed by a postictal right hemiplegia. On day 156 the baboon had a further series of seizures without recovery of consciousness and died.

Pathological findings The brain was macroscopically normal. The microscopical changes were representative of the lesions in all the specimens.

The most striking feature was diffuse moderately severe oedema of the white matter, accompanied by marked swelling of oligodendroglia. This was present throughout the white matter of the centrum ovale (Fig. 3), in such major tracts as the internal capsule, in the cerebellar white matter, and to a lesser extent in the pons and medulla. Special stains showed little or no destruction of myelin sheaths in most areas, no degenerating axons, and only scanty perivascular cells containing lipid debris scattered throughout the centrum ovale. The cerebral cortex, basal ganglia, and brain stem nuclei appeared normal but there was patchy radial gliosis of superficial parts of cerebellar folia. Chromatolysis of cortical neurones was not seen.

No lesions of intracerebral blood vessels were seen. The optic nerves, choroid plexus, and leptomeninges appeared normal.

\section{Baboon 4 (Fig. 2)}

Female $10.7 \mathrm{~kg}$. Injections of lead carbonate, $1 \mathrm{~g}$ (94 mg/kg initial weight), were given on days 0 and $24,0.8 \mathrm{~g}$ on day 42 , and $1 \mathrm{~g}$ on days $59,66,130$, 196 , and 234. Grand mal seizures without focal onset were observed on days 95 and 140 . On day 256 clinical evidence of pneumonia appeared and the animal died on day 265 .

Pathological findings The brain was macroscopically normal. Histological examination showed moderate generalized oedema of cerebral and cerebellar white matter and swelling of oligodendroglia. There was no evidence of demyelination, axonal degeneration or widespread gliosis of the centrum ovale. In the cerebral cortex, especially in watershed zones between the territories supplied by major cerebral arteries, there were occasional small scattered areas of pseudolaminar necrosis up to $300 \mu \mathrm{m}$ in diameter with focal loss of neurones, coarse sponginess of the neuropil, and local proliferation of astrocytes (Fig. 4). The majority of these 


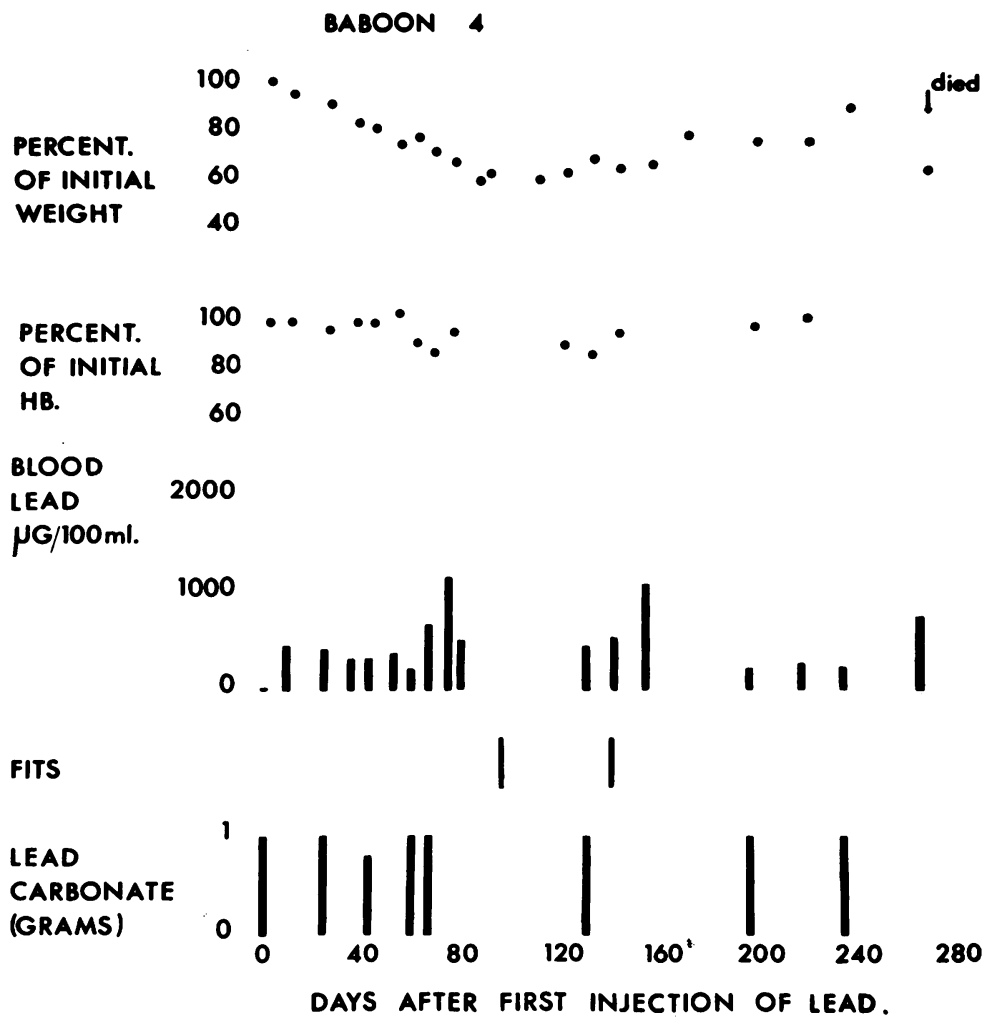

FIG. 2. Changes in body weight, in concentrations of haemoglobin and blood lead, and occurrence of fits after repeated intratracheal injections of lead carbonate in baboon 4 .

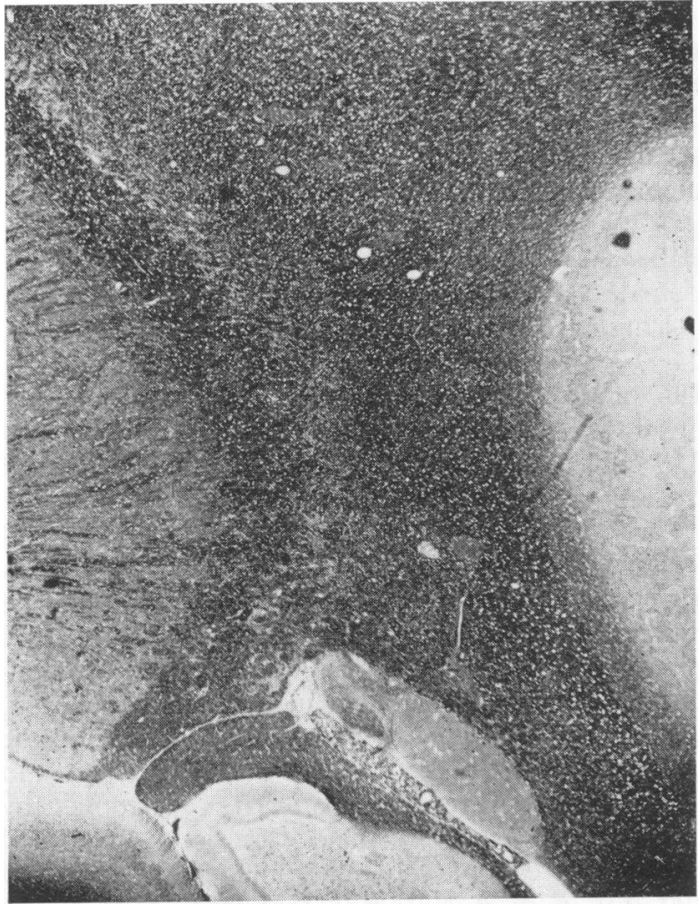

FIG. 3. Baboon 3. Extensive spongy oedema of white matter of centrum semiovale. (PTAH $\times 14$ ).

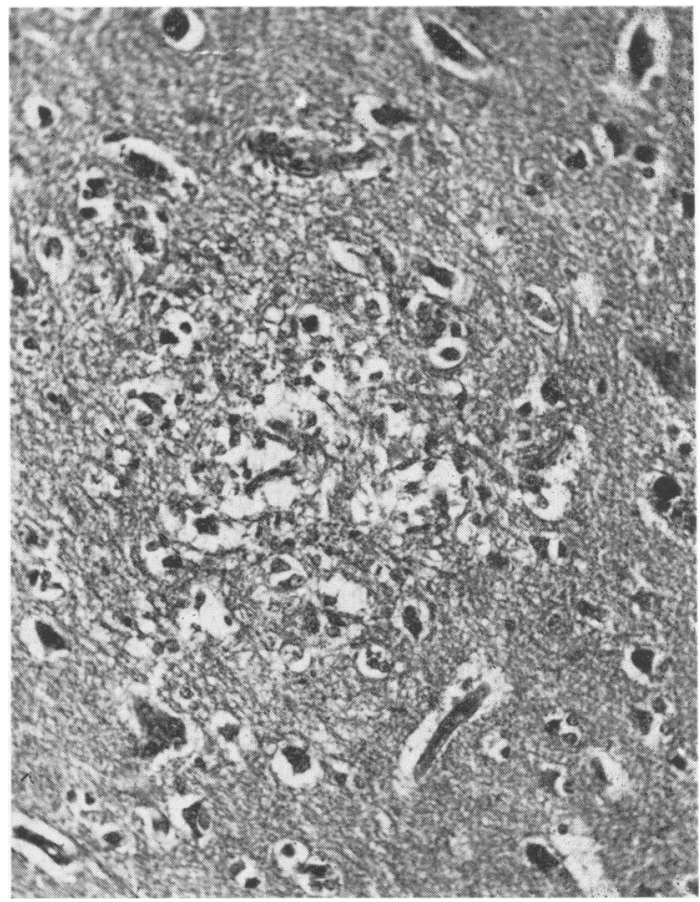

FIG. 4. Baboon 4. Focal necrosis in cerebral cortex. (H. and E. $\times 205)$. 


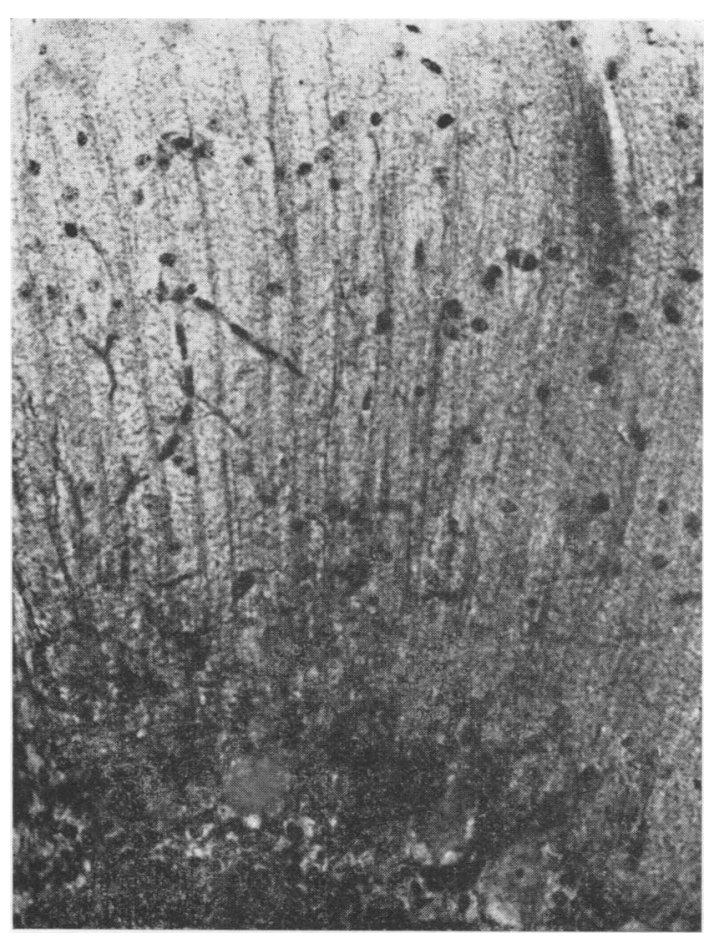

FIG. 5. Baboon 4. Radial gliosis in molecular layer of cerebellar cortex. (PTAH $\times$ 255).

were in laminae 3, 4 and 5. The hippocampal and Ammon's horn regions appeared normal. In the cerebellum there were irregular scattered areas of radial gliosis of the cortex associated with focal loss of Purkinje cells (Fig. 5). Neurons in the cerebral cortex did not show chromatolysis. No abnormality was seen of intracerebral blood vessels.

\section{Baboon 7B (Fig. 1)}

Infant female $2 \cdot 8 \mathrm{~kg}$, dentition $212 / 212$. An injection of lead carbonate, $150 \mathrm{mg}$ ( $54 \mathrm{mg} / \mathrm{kg}$ initial weight), was given on day $0,400 \mathrm{mg}$ on day $35,600 \mathrm{mg}$ on day 52 , and $1000 \mathrm{mg}$ on day 84 . No seizures were seen but weakness of hindquarters developed on day 107 and the baboon died on day 117 .

Pathological findings There again appeared to be generalized oedema of the white matter and no abnormality of cerebral vessels.

\section{Discussion}

Seizures have never been observed in our control baboons nor in those also observed for long periods during a study of intoxication by acrylamide (Hopkins and Gilliatt, 1971).

Therefore the seizures observed in two out of the three lead-intoxicated baboons reported here ( 8 out of 12 of all lead-intoxicated baboons observed in our laboratory (Hopkins, 1970)) clearly indicate that lead produces an encephalopathy in this primate. Furthermore, there are reports of seizures due to lead encephalopathy in captive primates in zoos, the usual source of lead being paint from the cage (see Zook (1971) for references). Zook reported demyelination as a major finding in the brain and spinal cord of some of these apparently leadintoxicated caged primates. but this might well be due to the $B_{12}$ deficiency which is known to occur in monkey colonies (Oxnard and Smith, 1966). All our experimental animals received $1000 \mu \mathrm{g}$ of $\mathrm{B}_{12}$ monthly, and demyelination was not seen.

The pathological findings in the present animals may be discussed under two headings: cerebral oedema, and focal cortical necroses. Oedema was generalized throughout the white matter, as shown by pallor of myelin staining and, if severe, by separation of myelinated fibres by small amounts of clear fluid which sometimes formed pools around the smaller blood vessels. It was accompanied by visible and often quite marked swelling of oligodendroglial cytoplasm, which produced the appearance of perinuclear halos. The changes are common to most forms of cerebral oedema (Blackwood et al., 1963). Similar appearances were not found in the control animal and so they cannot be attributed to agonal changes. The other lesion, focal cortical necrosis, was manifested as pseudolaminar areas of spongy change and scarring in the cerebral cortex, and as zones of gliosis in the molecular layer of the cerebellar cortex. The nature and topographic distribution of these changes makes it very likely that they were due to epileptic convulsions which may well have been more numerous than were observed.

Several different lesions have been considered of importance in lead encephalopathy (Pentschew, 1958). For some authors, the primary or most important pathological change lies in the nerve cell (Nissl, 1892; Ferraro and Hernandez, 1932). The latter authors, working with lead-intoxicated cats and monkeys, described chromatolysis, vacuolization, and liquefaction of neurons diffusely throughout the cerebrum. For other workers the primary or most important change is in the neuroglia. Vizioli (1929) described acute swelling on micro- and oligodendroglia in lead-intoxicated rabbits, and Roberti (1931) noted astrocytic proliferation. Other workers described meningeal involvement in lead encephalopathy. Hassin (1921) found a proliferative meningitis and round cell infiltration of the meninges, and in the recent series of Whitfield et al. (1972) a third of 23 patients had an increased number of cells in the cerebrospinal fluid. Yet another view is expressed in the monograph of Cantarow and Trumper (1944), who suggested that 'many if not indeed the majority 
of the clinical manifestations of lead encephalopathy are dependent upon, or associated with hypertension, which some authorities believe to be invariably present in this condition'. Although it must be admitted that the chronic nephritis caused by lead poisoning may produce hypertension and that encephalopathy may be accompanied by papilloedema, there are numerous reports of encephalopathy occurring in normotensive patients (e.g., Akelaitis, 1941; Whitfield et al., 1972).

Some reports of human and experimental lead encephalopathy underline the importance of the vascular changes, although it has been difficult to disentangle agonal and postmortem changes in the appearances and staining properties of parenchymal and stromal cells and blood vessels. Mott (1909) described multiple haemorrhages in the brain and cord in a patient with encephalopathy which appear to have been similar to those produced experimentally by Goadby and Goodbody (1909) in cats in the same year. The presence of endothelial proliferation in small blood vessels and the presence of new capillaries and dilatation of existing ones has been clearly described by a number of recent authors (see Whitfield et al. (1972) for references). Pentschew (1965) is perhaps the most vigorous proponent of the hypothesis that the vascular changes are a most important feature. In a review of necropsy material from 20 children with lead encephalopathy he described 'capillary activation' (dilatation of capillaries and swelling of endothelial cells) which was most marked in the molecular layer of the cerebellar cortex. Astrocytic proliferation and perivascular cuffing was also present, which Pentschew regarded as 'the earliest morphologic response to a dysfunction of the blood-brain barrier'. Pentschew and Garro (1966) have produced lead encephalopathy in suckling rats. The entire cerebellum in these animals looked reddish-brown due to large numbers of microscopic haemorrhages. There was also intense glial proliferation and serous exudates with marked capillary proliferation. Neurons remained almost entirely normal. Injection of trypan blue revealed the extent of the breakdown of the blood-brain barrier, the white matter of the cerebral hemisphere, the rostral part of the striatum, and the spinal cord staining intensely blue. Lead-intoxicated suckling rats have more recently been studied by Thomas, Dallenbach, and Thomas (1971). Many capillaries in the cerebellum were found to be lined by degenerating swollen endothelial cells, and others were occluded by aggregates of platelets and formation of thrombi. Oedema fluid collected in the perivascular end-processes of astroglia and later coalesced to form perivascular lakes, as in the present study. Purkinje cells appeared pyknotic, and the authors considered this to be secondary to anoxia resulting from the described changes in the capillary circulation.
There is only one previous pathological study of the brains of lead-intoxicated primates. Ferraro and Hernandez (1932), investigating the neuropathology of lead poisoning, administered lead carbonate to two monkeys (species unnamed). Monkey 1 received $1.03 \mathrm{~g} /$ day by mouth and monkey $21.07 \mathrm{~g} /$ day. Symptoms of 'vomiting, diarrhoea, anorexia, emaciation and general weakness, etc.' began on the 12th day in monkey 1 and on the 16th day in monkey 2 . Monkey 1 lost $8 \%$ of its body weight, monkey 2 lost $12 \%$. Both animals died on the 66th day. Diffuse changes were found in the nervous system of both animals. Chromatolysis, vacuolization, and liquefaction of the nerve cells occurred in the cerebral cortex, particularly in the layer of small pyramidal cells; astrocytes were increased in number and size in the white matter, and blood vessels showed endothelial swelling. Unfortunately almost all the changes described could represent nonspecific agonal effects of anoxia (exacerbated by convulsions), hypertension if present, and secondary reactive changes in blood vessels in areas of cerebral oedema. The only definite changes are the occurrence of an encephalopathy associated with cerebral oedema too severe and too widespread to be a terminal event and of convulsions accompanied by post-epileptic brain damage. The experiments of Pentschew and Garro (1966), in which trypan blue injected into suckling rats with lead encephalopathy was shown to leak into the cerebellum, provide further support for the contention that cerebral oedema develops as an integral part of the pathological effects of lead poisoning. Caution is required in interpreting these experiments, however, because the anoxia associated with convulsions may also cause abnormal permeability of blood vessels.

The present experiments have not afforded any evidence about the pathogenesis of the cerebral oedema, nor have they given any clue to possible links between the cerebral lesion and the damage produced by lead in peripheral nerves. Further critical studies should be of interest clinically as well as pathologically because there are few known and controllable causes of oedema of the brain.

A. P. Hopkins was supported by a grant from the Medical Research Council which is gratefully acknowledged.

\section{References}

Akelaitis, A. J. (1941). Lead encephalopathy in children and adults: a clinico-pathological study. Journal of Nervous and Mental Diseases, 93, 313-332.

Blackwood, W., McMenemey, W. H., Meyer, A., Norman, R. M., and Russell, D. S. (1963). Greenfield's Neuropathology. Edward Arnold, London.

Cantarow, H. and Trumper, M. (1944). Lead Poisoning. Williams and Wilkins, Baltimore.

Ferraro, A. and Hernandez, R. (1932). Lead poisoning. (A 
histopathological study of the nervous system of cats and monkeys in the acute and subacute stages.) Psychiatric Quarterly, 6, 121-146 and 319-350.

Goadby, K. W. and Goodbody, F. W. (1909). A note on the pathology of lead poisoning. Lancet, 2, 988-991.

Hassin, G. B. (1921). The contrast between the brain lesions produced by lead and other inorganic poisons and those caused by epidemic encephalitis. Archives of Neurology' and Psychiatry (Chicago), 6, 268-285.

Hopkins, A. P. (1970). Experimental lead poisoning in the baboon. British Journal of Industrial Medicine, 27, $130-140$.

_ conduction velocity in the baboon: normal values and changes during acrylamide neuropathy. Journal of Neurology, Neurosurgery and Psychiatry, 34, 415-426.

Mott, F. W. (1909). Examination of the nervous system in a case of chronic lead encephalitis. Archives of Neurology and : sychiatry (London), 4, 117-130.

Nissl, F. (1892). Ueber experimentell erzeugte Veränderungen an den Vorderhornzellen des Rükenmarks bei Kaninchen mit Demonstration mikroskopischer Präparate. Allgemeine Zeitschrift für Psychiatrie, 48, 675-682.

Oxnard, C. E. and Smith, W. T. (1966). Neurological degeneration and reduced serum vitamin $B_{12}$-levels in captive monkeys. Nature, 210, 507-509.

Pentschew, A. (1958). Bleivergiftung. In Handbuch der spezielle pathologische Anatomie, edited by $O$. Lubarsch, F. Henke, and R. Rössle, bd 13, 2B, pp. 1929-1970. Springer-Verlag, Berlin.
(1965). Morphology and morphogenesis of lead encephalopathy. Acta Neuropathologica, 5, 133-160.

- and Garro, F. (1966). Lead encephalo-myelopathy of the suckling rat and its implications on the porphyrinopathic nervous diseases, with special reference to the permeability disorders of the nervous system's capillaries. Acta Neuropathologica, 6, 266-278.

Roberti, C. E. (1931). Sul comportamento della macroglia e degli elementi nervosi nelle intossicazioni sperimentali da: istammina guanidina, acido cloridrico, acetato di piombi e acetato talloso. Rassegna di Studi Psichiatrici, 20, 7-29.

Thomas, J. A., Dallenbach, F. D., and Thomas, M. (1971). Considerations in the development of experimental lead encephalopathy. Virchows Archiv für pathologische Anatomie und Physiologie und für klinische Medizin, 352, 61-74.

Vizioli, F. (1929). La microglia e l'oligodendroglia nelle intossicazioni sperimentali e nelle alterazioni postmortali. Rivista di Neurologia, 2, 365-386.

Whitfield, C. L., Ch'ien, L. T., and Whitehead, J. D. (1972). Lead encephalopathy in adults. American Journal of Medicine, 52, 289-298.

Zook, B. C. (1971). An animal model for human disease. Comparative Pathology Bulletin, 3, 3-4.

Received for publication 9 August, 1973.

Accepted for publication 26 November, 1973. 